Social Networking Site Use and Materialistic Values among the Youth: The Safeguarding Role of Parent-Child Relationship and Self-Regulation

\author{
Hillbun Ho \\ Fellow of Institute on Asian Consumer Insight \\ Nanyang Technological University \\ 50 Nanyang Avenue \\ Singapore 639798 \\ Tel.: +65 67904980 \\ Email: dixonho@ntu.edu.sg \\ Senior Lecturer \\ Marketing Discipline Group \\ University of Technology Sydney \\ 15 Broadway \\ Ultimo 2007 \\ NSW, Australia \\ Wonsun Shin \\ Senior Lecturer \\ School of Culture and Communication \\ 141 John Medley Building \\ University of Melbourne \\ Parkville 3010 \\ VIC, Australia \\ Email: wonsun.shin@unimelb.edu.au \\ May O. Lwin \\ Professor \\ Wee Kim Wee School of Communication and Information \\ College of Humanities, Arts, \& Social Sciences \\ Nanyang Technological University \\ 31 Nanyang Link \\ Singapore 637718 \\ Tel.: +65 67906669 \\ Email: tmaylwin@ntu.edu.sg
}




\title{
Social Networking Site Use and Materialistic Values among Youth: The Safeguarding Role of the Parent-Child Relationship and Self-Regulation
}

\begin{abstract}
Social networking sites (SNSs) have become common avenues for young people to share their life experience with peers, including their consumption experience. Although prior research on the media effects of SNSs has shown how online communication on SNSs promotes various volitional behaviors, current understanding is limited with respect to how young people's use of SNSs is associated with their consumption experience and materialistic values. This study examines how SNS use related to consumption experience is associated with materialistic values among young adults and how their social perceptions mediate such association. This investigation also proposes that young adults' self-regulation and close relationships with parents would buffer the impact of SNS use. Survey data gathered from 903 youths in Singapore lend strong empirical support to the hypotheses proposed. Implications are discussed.
\end{abstract}

\section{Keywords}

social network site, materialism, self-regulation, parent-child relationship, social perception 


\section{Introduction}

With the recent rapid diffusion of social networking sites (SNSs) such as Facebook, Twitter, and Instagram, youths all over the world have been spending increasing amounts of time on social media (Pew Research Center, 2015). Millennials, who grew up during the rapid evolution of the digital world, are especially accustomed to communicating with their social networks through SNSs. Compared with traditional mass media, SNSs are distinctive in that they allow users to create content about their daily lives and share that content with their peers. Such "selfexpression” opportunities provided by SNSs could have a significant influence on the nature of messages that users share and their responses to messages from other users (Pingree, 2007). For this reason, SNS-mediated communication among youths has drawn increasing attention from communication scholars (Valkenburg, Peter, \& Walther, 2016).

The consumer culture prevalent in developed economies suggests that symbols and artifacts of consumerism are often embedded in the content shared by users on SNSs (Greene, 2012). These symbols include, for example, advertisements of brands and luxury goods, fashion portraits, and photos of fine dining and holiday trips (Dittmar, 2007; Hirschman \& Thompson, 1997). Prior research has revealed that young people’s exposure to mass media leads to stronger materialism through cultivation processes (Shrum, Burroughs, \& Rindfleisch, 2005; Shrum, Lee, Burroughs, \& Rindfleisch, 2011). Materialism refers to the importance individuals ascribe to the ownership and acquisition of material goods in achieving major life goals or desired states (Richins, 2004). Surprisingly, little is known about how young people’s use of SNSs is associated with their consumption experience and materialism. However, this issue is of substantive importance, because youths today tend to spend more time on SNSs than on traditional media and rely increasingly on SNSs to access news and catch up consumption trends 
(Pew Research Center, 2015; We are social: digital, social and mobile, 2015). More importantly, the vivid and polished visuals shared by SNS users could be a readily available and salient frame of reference for social comparisons, with potential negative impact on psychological health and well-being (Dittmar, 2007; Haferkamp, Eimler, Papadakis, \& Kruck, 2012).

Considerable evidence in prior research has shown that individuals with elevated materialistic values experience poor well-being, anxiety, and life dissatisfaction (Dittmar, Bond, Hurst, \& Kasser, 2014). Our study anticipates that, like representations on television, SNSs can shape youths' beliefs regarding material possessions and financial success. That is, frequent exposure to content and messages about acquisition and consumption of material possessions may heighten young people's materialism. In addition, in response to the call to examine dispositional and family factors as moderators of media effects (Valkenburg \& Peter, 2013), this study investigates self-regulation and parent-child relationship quality as potential buffers against the adverse impact of consumption-oriented SNS use. We focus on these two factors because prior research indicates that they are likely to curb materialism of young people (Chaplin \& John, 2010; Faber \& Vohs, 2011) and they play an important role in youths' digital media use (Li, Li, \& Newman, 2013; Yao, He, Ko, \& Pang, 2015). In addition, prior research has shown that both self-regulation and parent-child relationship quality are associated with young people's psychological functioning (Lamborn, Mounts, Steinberg, \& Dornbusch, 1991; Wills, Pokhrel, Morehouse, \& Fenster, 2011), which would affect their inclination to engage in risk behaviors including behaviors on the Internet. Therefore, studying these two factors would provide valuable insights for understanding the boundary conditions for the effects of SNS use.

Singapore served as the locale for the current study for several reasons. Singapore today places heavy emphasis on economic prosperity, which is reflected in the consumption patterns of 
its people (70\% of Singaporeans, 2011; Chia, 2010). Singaporeans rate material life as highly important, and this centrality is succinctly captured by the country's infamous cultural ethos of the "5Cs" (i.e., cash, car, credit card, condominium, and country club), which Singaporeans believe are indispensable to their lives (Keng, Kwon, Tan, \& Wirtz, 2000). Research has also suggested that materialism is the culprit for Singapore's increasing number of single adults, strained marital relationships, and low fertility rate (Li, Patel, Balliet, Tov, \& Scollon, 2011). In addition, the levels of Internet penetration and time spent on social media are similar between Singapore and other developed countries (We are social: digital, social and mobile, 2015). Thus, the socioeconomic environment in the country provides a highly suitable context for studying phenomena related to materialism and the use of SNSs. The findings of this study should offer relevant insights to comparable developed societies.

Overall, this study contributes to the communication literature in several ways. First, it demonstrates how computer-mediated communication on SNSs affects the beliefs and values of youths. Second, it offers theoretical explanations for the effects of consumption-oriented SNS use on youths' materialism and empirically validates such effects. Third, it proposes and tests both family (parent-child relationship quality) and personal (self-regulation) factors that would moderate the impact of consumption-oriented SNS use and thus reveals the traits of young people who are more or less vulnerable to the negative repercussions of new media use.

\section{Literature Review and Hypotheses}

\section{Social Networking Site Use}

SNSs allow users to create public profiles, maintain offline relationships, connect with other users who share similar interests, and communicate with their social networks. Users can communicate with each other using a variety of tools, such as chatting, sending private 
messages, leaving public comments on posts, linking to content from other sources, and sharing photos and videos (boyd \& Ellison, 2007; Nadkarni \& Hofmann, 2012). A recent study indicated that $89 \%$ of young people in the US use SNSs and that $43 \%$ of Facebook users sign in to the site multiple times per day (Pew Research Center, 2015). By comparison, in Singapore 91\% of Internet users use SNSs and 35\% of young people spend more than 10 hours per day on the Internet, with 83\% of young people visiting SNSs at least once a day (National Youth Council, 2014; We are social: digital, social and mobile, 2015). Since SNSs enable users to traverse their proximate and distal social connections, maintain a large, diverse network, and access information about others, SNSs offer avenues for socialization within the online space, vastly expanding opportunities for sharing personal interests and experiences (Ellison \& boyd, 2013). Previous studies have examined various uses of SNSs, including political engagement (Kim Hsu, \& Gil de Zúñiga, 2013), volunteer work (Farrow \& Yuan, 2011), and social capital formation (Ellison, Vitak, Gray, \& Lampe, 2014). These studies suggest that SNSs can fulfill individuals' needs for identity, community connection, information, and recreation. Adding to this literature, the present study examines a specific use of SNSs that fulfills individuals' needs to communicate with peers regarding their consumption experiences and assesses the implications in fostering young people's materialism. We define consumption-oriented use of SNSs as individuals' use of SNSs to access marketing messages and communicate with peers with respect to goods, spending, and consumption activities. These pursuits include posting pictures of material possessions, commenting on peers' pictures of consumption activities (e.g., fine dining and holidays at a luxury resort), and forwarding marketing messages to peers. In addition, we suggest that consumption-oriented use of SNSs is a construct composed of two dimensions. One dimension reflects personal communication with peers regarding consumption 
topics, whereas the other dimension reflects non-personal communication with marketers such as viewing and responding to advertisements and messages from favorite brands. We consider these two forms of communication to be the components of consumption-oriented SNS use because today, most SNSs not only function as communication platforms for users to share content with their peers but also serve as channels for companies to promote products and brands (Beukeboom, Kerkhof, \& de Vries, 2015). Therefore, SNS users are exposed to a myriad of marketing messages and might seek out marketing information deliberately by connecting with companies’ marketing and promotion sites.

\section{Cultivation Effects and Social Networking Sites}

According to cultivation theory (Gerbner, 1994), media usage cultivates its users' belief in a real world that resembles the world depicted in media messages through the most stable and recurrent portrayals in media, particularly television. Cultivation effects induce two forms of judgments among media users: (a) an individual's perception of the prevalence of social phenomena such as violence and affluence—first-order effects—and (b) judgments that indicate a person's beliefs and attitudes, such as fear of crime—-second-order effects (Gerbner, 1994; Morgan \& Shanahan, 2010).

As noted, studies concerning cultivation effects on perceptions, such as the perceived level of affluence or violence in a society, have demonstrated biases in heavy media users' beliefs regarding real-world phenomena, to the effect that these phenomena resemble the television world (Morgan \& Shanahan, 2010). The social cognitive perspective of cultivation research has demonstrated that such effects arise from heavy viewers' use of spontaneously recalled vivid, easily accessible, salient television images stored in memory to form social judgments (Shrum, 1995). Frequent viewing and usage of media increase accessibility of 
relevant exemplars in memory, which in turn affect viewers’ social perceptions (Shrum, 2001; Shrum et al., 2011).

Recent research on cultivation effects has addressed broader implications of television viewing, such as the specific impact of program genres and local news (Lee \& Niederdeppe, 2011) and the effects on viewers' behaviors and well-being (Beullens, Roe, \& Van den Bulck, 2011; Martins \& Harrison, 2012), as well as impacts on viewers’ value judgments across various social arenas (Morgan \& Shanahan, 2010). Prior research has also validated the effects of television viewing on young viewers’ heightened materialism and impaired well-being (Opree, Buijzen, Van Reijmersdal, \& Valkenburg, 2014; Sirgy et al., 2012). Cultivation effects studies have shown that heavy television viewers tend to overestimate the level of affluence across households in a society and engage in upward social comparisons (O’Guinn \& Shrum, 1997; Shrum et al., 2011). Although these studies have advanced understanding of cultivation effects, very little research has forayed into the domain of the new media (Morgan, Shanahan, \& Signoielli, 2015).

To understand the media effects of SNSs vis-à-vis traditional mass media, we consider the resemblances and differences between traditional media use (i.e., television viewing) and SNS use. Compared to television viewers, users of SNS are less passive with regard to media messages, as they can produce and distribute content to their peers and other users. SNSs also allow recipients to respond to content and communicate with the content providers. Thus, the new media enable bilateral communication about the shared content and messages between senders and recipients (Brandtzæg, 2012). SNSs have also become important channels for companies to promote products and brands through targeted marketing messages (Beukeboom, et al., 2015). 
In light of these characteristics, messages on SNSs appear to be more personally relevant and salient to users as compared to messages on television, which facilitates the encoding and recall of such messages—a key cognitive process underpinning cultivation effects (Johar, Maheswaran, \& Peracchio, 2006; Shrum et al., 2011). Therefore, we expect that consumptionoriented use of SNSs will shape users' beliefs regarding material possessions and that such effects could be attributed to cultivation effects. By showing how SNS use alleviates materialism through social perceptions among young people, the present study could introduce new insights to the media-effects literature.

\section{Consumption-oriented SNS Use and Materialism}

As discussed earlier, a large body of research has established that mass media shape young viewers' beliefs, values, and behaviors (Dubow, Huesmann, \& Greenwood, 2007). For instance, frequent exposure to mass media related to sex, violence, and smoking can change young people's attitudes toward and participation in related risky behaviors (Brown \& L’Engle, 2009; Slater, Henry, Swaim, \& Anderson, 2003; Slater \& Hayes, 2010). In addition, studies of advertising effects have demonstrated that mass media shape youths’ materialism (Buijzen \& Valkenburg, 2003; Chia, 2010; Opree et al., 2014). In both survey and laboratory studies, cultivation research has also found that television viewing leads to materialism (Shrum et al., 2005).

Symbols and artifacts of consumer culture, such as brand logos, luxury goods, designer clothing, and fashion models, are prevalent in mass media (Dittmar, 2007). Images in mass media also "provide prototypic expectations about the consumption patterns (e.g., dress, food preferences, leisure activities, appearance characteristics of persons who are rich/poor, young/old, male/female, and blue collar/professional)” (Hirschman \& Thompson, 1997, p. 44). 
Given the widespread use of SNSs among users with wide-ranging demographics, the content appearing on SNSs are likely to be imbued with elements of consumer culture (Lewis, Kaufman, Gonzalez, Wimmer, \& Christakis, 2008). Frequent exposure to consumption-related content could readily shape users' attitudes toward material possessions and wealth, especially among youths, who tend to be susceptible to media influence (Dubow et al. 2007; Shrum et al., 2005). In addition, since SNS users maintain a large diverse virtual network, their beliefs and attitudes could be easily altered by viewing and sharing content of personal interest (Bode, Vraga, Borah, \& Shah, 2014; Lee et al., 2014). Through reading the consumption-related content distributed by peers and responding to such content as a relational gesture (Ellison et al., 2014), young people’s attitudes toward spending, possessions, and consumption might gradually conform to those of their peers. As a result, we predict that a positive relationship exists between materialism and consumption-oriented SNS use (i.e., access to marketing messages and communication with peers with respect to goods, spending, and consumption activities on SNSs):

Hypothesis 1a (H1a): Consumption-oriented SNS use has a positive relationship with young users' materialism.

Cultivation theory suggests that heavy television viewers' perceptions of social reality resemble dominant television portrayals and be biased upward (e.g., an inflated estimation of affluence and violence in society that resembles television portrayals) (Morgan \& Shanahan, 2010). In line with this contention, we suggest that frequent viewing of consumption-related content on SNSs would lead users to overestimate their peers' level of spending and consumption (Chou \& Edge, 2012). This effect could be attributed to users' automatic encoding and retrieval of the consumption images appearing on SNSs (Shrum et al., 2005). Also, young users of SNSs tend to create and share content actively, which could elevate attention to the 
consumption symbols embedded in peers’ photos and messages (Smith, Fischer, \& Chen, 2012). These premises are in line with findings in prior research showing that after viewing others' photos posted on SNSs, young users of SNSs see other users as more attractive and competent than themselves (de Vries \& Kuhne, 2015; Fardouly, Diedrichs, Vartanian, \& Halliwell, 2015;

Kim \& Chock, 2015). Accordingly, SNS users’ social perception of peers’ spending may account for the association between consumption-oriented SNS use and materialism. On the basis of the above discussion, we propose the following hypothesis:

Hypothesis 1b (H1b): Consumption-oriented SNS use has a positive, indirect relationship with young users' materialism through the mediation of perception of peers’ spending levels (social perception).

\section{Moderating Effects of Parent-Child Relationship Quality}

Literature in developmental psychology illustrates that parents have a significant impact on their children’s values and beliefs. For example, research shows that children of non-nurturing mothers tend to place greater importance on financial success than on affiliative, community, and self-acceptance values. In contrast, children of mothers who have warm and democratic parenting styles place greater value on prosocial behaviors (Kasser, Ryan, Zax, \& Sameroff, 1995). In addition, previous studies have found that quality parent-child interactions and supportive parenting contribute to the development of children’s prosocial and empathic orientation, increase the likelihood that adolescents view parental values as desirable (Allen Hauser, Bell, \& O’Connor, 1994; Collins \& Laursen, 2004), and lead to positive psychological functioning in adolescents, which continues into adulthood (Lamborn et al., 1991). Research has also shown that supportive parenting boosts children's self-esteem and curbs their materialism (Chaplin \& John, 2010). In contrast, young adults who grew up in disrupted families tend to 
endorse materialistic values and engage in compulsive buying — the result of living in an unstable family environment and using possessions as a means to cope with stressful life events and assess their self-worth (Rindfleisch, Burroughs, \& Denton, 1997).

With regard to parents' effect on children's media use, research on parental mediation has demonstrated that parents can mitigate undesirable media effects on their children, such as media-induced aggression (Nathanson, 2004), advertising-induced materialism (Buijzen \& Valkenburg, 2005), and unhealthy food consumption (Buijzen, Schuurman, \& Bomhof, 2008). Parents can also induce desirable outcomes, such as learning from educational television programs (Valkenburg, Krcmar, \& De Roos, 1998) and heightened awareness of online privacy issues (Lwin, Stanaland, \& Miyazaki, 2008; Shin \& Kang, 2016). A consistent finding in this literature is that mediation based on parent-child open discussion and bilateral dialogue is more effective than mediation based on restriction and control (Buijzen \& Valkenburg, 2005; Nathanson, 1999; Lwin et al., 2008), which is in line with findings of the previously mentioned developmental psychology research.

On the basis of the above evidence, we propose that high-quality parent-child interactions and relationships provide a secure family environment that supports self-acceptance and satisfies intrinsic needs crucial to psychological well-being. By parent-child relationship quality, we refer to the emotional support individuals receive from their parents and the closeness of the relationship. Thus, high-quality parent-child relationships are characterized by mutual communication, high levels of emotional support, and satisfaction with the relationship. Prior research indicates that high-quality parent-child relationships entail open parent-child discussion of issues related to media use and consumption, which in turn provides youths with opportunities to develop critical thinking skills (Fujioka \& Austin, 2003). As a result, those who 
grew up in a warm and supportive family environment with high-quality parent-child relationships are less likely to emphasize materialistic values over other values important to happiness and life satisfaction (Dittmar et al., 2014). They would adjust better in the transition to adulthood and have a greater propensity to behave in a prosocial, responsible manner. As a result, young adults would be less susceptible to the influence of mass media as well as consumption-related SNS use. Therefore, we predict that parent-child relationship quality would buffer the impact of consumption-oriented SNS use on young users' materialism:

Hypothesis 2 (H2): Parent-child relationship quality negatively moderates the relationship between consumption-oriented SNS use and materialism.

\section{Moderating Effects of Self-regulation Competence}

Self-regulation refers to individuals' ability to overcome their impulses and adjust their course of action in the pursuit of valuable personal goals over time (Barkley, 2004; Bauer \& Baumeister, 2011; Moilanen, 2007). Competence in self-regulation helps individuals deal with conflicts in tasks and orchestrate thoughts and actions in goal-directed behaviors (Blair \& Ursache, 2011). Therefore, high self-regulation competence is associated with such psychosocial functioning attributes as the tendency to plan ahead, the ability to consider alternatives before acting, and the capacity to link behaviors with long-term consequences, whereas low self-regulation competence is characterized by attributes such as being impatient and distractible, having difficulty in delaying gratification, and being easily frustrated (Wills et al., 2011). Previous studies have found that youth suffering from chronic depletion of self-regulatory resources engage in unhealthy behaviors such as compulsive buying (Faber \& Vohs, 2011), Internet addiction (LaRose, Lin, \& Eastin, 2003), and substance abuse (Wills et al., 2011). 
Individuals with high self-regulation competence display restraint in undesirable behaviors that offer instant gratification, and instead direct their attention, emotion, and behaviors toward pursuing long-term goals with positive outcomes. Prior research shows that adolescents with high competence in self-regulation enjoy a variety of benefits, such as good academic performance and a lower likelihood of substance use (Blair \& Diamond, 2008; Wills et al., 2011). Adolescents high on self-regulation also exhibit a stronger pro-social disposition and fewer transgressive behaviors (Bandura, Caprara, Barbaranelli, Pastorelli, \& Regalia, 2001), and refrain from risky behaviors such as smoking, drinking alcohol, substance use, and unsafe sexual activities (Dvorak \& Day, 2014; Novak \& Clayton, 2001; Quinn \& Fromme, 2010).

The aforementioned work suggests that self-regulation competence protects young people from being affected by external agents and events that could trigger delinquent behaviors or from repeatedly exercising certain behaviors that satiate immediate desires but have harmful consequences over time. Examination of such buffering effects against risk factors shows that self-regulation competence mitigates the effects of heavy episodic alcohol drinking on alcoholrelated problems and unprotected sex among young adults (Quinn \& Fromme, 2010). Further, self-regulation competence moderates the impact of negative life events and affiliation with substance-using peers on youths’ substance use and related problems (Wills et al., 2011).

In the current study, we argue that self-regulation competence could to some extent shield young adults from the harmful effects of consumption-oriented SNS use. Through inhibitory control and attention shifting in self-regulatory processes (Bridgett, Burt, Edwards, \& DeaterDeckard, 2015), highly self-regulated young adults could avoid paying excessive attention to the consumption-oriented content on SNSs and control their affective and emotional response to such content (Baumeister \& Heatherton, 1996). In other words, highly self-regulated individuals 
are able to inhibit indulgent thoughts about the material goods and consumption activities they are exposed to on SNSs. Therefore, we predict that self-regulation competence would buffer the impact of consumption-oriented SNS use on young users' materialism:

Hypothesis 3 (H3): Self-regulation competence negatively moderates the relationship between consumption-oriented SNS use and materialism.

\section{Method}

\section{Participants}

Surveys approved by the university ethics review board were conducted on the campuses of three universities and two polytechnic institutes in Singapore in late 2014. The selected institutions offer a comprehensive portfolio of programs and have the highest numbers of enrollment and demographically diverse student populations in Singapore. Trained research assistants administered the paper-and-pencil surveys on the campuses of the selected institutions. Participants were undergraduates recruited by research assistants through convenience sampling in public studying areas on weekdays. Each participant was given a self-administered survey together with a consent form. The consent form stated the purpose of the study and the rights of the participants, and offered a monetary incentive (equivalent to US\$4). After completing the survey, each participant returned it to the research assistants and received the incentive. At the end of the data collection period, 903 completed responses had been received. Participants ranged in age from 17 to 24 years $(M=19.60, S D=1.62)$ and $46 \%$ were male. In line with the demographics of students enrolled in the tertiary-education institutions in Singapore, the majority (86.8\%) were Chinese, 5.9\% were Malay, $4.6 \%$ were Indian, and 2.7\% belonged to other racial groups. 


\section{Measures}

We used existing scales from the literature whenever they were available. When no scale was available and applicable to our research context, we developed new scales grounded in a literature review and insights generated from four focus groups with undergraduate students who discussed their SNS use and purchase behaviors prior to the survey. All new scales were pretested with a group of 20 students to ensure comprehension, correctness, and high content validity.

Consumption-oriented SNS use. As mentioned earlier, consumption-oriented SNS use in this study refers to individuals' use of SNSs to access marketing messages and communicate with peers on topics such as products, spending, and consumption. Since no scale existed in the literature, we developed a new scale of eight items that capture the mediated communication on SNSs regarding products, spending, and consumption. The eight statements included items on posting photos, commenting on and reading peers’ posts, reading and forwarding marketing messages, and instant chat with peers. We anticipated this construct was composed of two dimensions. The first dimension assessed personal communication between users whereas the second dimension assessed non-personal communication with marketers (e.g., viewing and responding to advertisements and messages from favorite brands). A sample item for the first

dimension (subscale 1) was "Post photos of goods or clothing that you have just purchased” and a sample item for the second dimension (subscale 2) was "Pay attention to ads and visit websites linked to those ads.” Participants rated the frequency of their involvement in this consumptionoriented communication on a response scale ranging from $1=$ never to $5=$ always.

To assess the multi-dimensionality of the scale, we used exploratory factor analysis (EFA) followed by confirmatory factor analysis (CFA). Results of EFA using Varimax rotation 
suggested that as expected, the scale had two dimensions (Eigenvalue greater than one). The first factor consisted of six variables while the second factor consisted of two variables.

Subsequently, we used CFA to evaluate the two-dimensional scale represented as a second-order latent factor composed of two first-order latent factors. Results showed that all factor loadings were significant with excellent model fit $(\mathrm{NNFI}=.93, \mathrm{CFI}=.96$, SRMR $=.05$, RMSEA $=.08)$. Factor loadings of the two first-order factors were also significant and ranged from .57 to .89 for the first factor and .73 to .95 for the second factor. We compared model fit indices between this model and the model without the second-order factor and the results indicated that the latter model was acceptable but had less satisfactory model fit $(\mathrm{NNFI}=.92$, CFI $=.95$, SRMR $=.05$, RMSEA $=.09$ ). Reliability of both subscales was good (subscale 1: Cronbach's $\alpha=.85$; subscale 2: Cronbach's $\alpha=.78)$.

Social perception. We developed a new scale of three items to assess individuals' social perception. Participants rated three statements as to how accurately each statement described their perception of peers' level of spending ( $1=$ strong disagree to $6=$ strongly agree $)$. CFA results indicated that standardized loadings ranged from .54 to .86 . Reliability of the measure was acceptable (Cronbach’s $\alpha=.78)$.

Materialism. To assess materialism, we adopted the material values scale (Richins, 2004), which has been widely used in the psychology and consumer literature. The scale assesses the centrality of material possessions in a person's life as well as beliefs about improved success and happiness resulting from such acquisitions. Participants rated nine statements as to how accurately each statement described them, providing responses on a 6-point scale ( 1 = strongly disagree to 6 = strongly agree) . CFA results indicated that all factor loadings were significant with good model fit $(\mathrm{NNFI}=.92, \mathrm{CFI}=.95, \mathrm{SRMR}=.04, \mathrm{RMSEA}=.08)$. An item was deleted 
in subsequent analyses as its standardized loading was lower than the acceptable level of .40 (Bollan, 1989). Standardized loadings of the remaining items ranged from .58 to .79. Reliability of the measure was good (Cronbach's $\alpha=.87$ ).

Self-regulation. To measure individuals' self-regulation competence, we adopted the scale from Moilanen (2007) that assesses adolescents' ability to self-regulate in the long term. Participants rated 14 statements on the basis of the degree to which they felt each statement described them, providing responses on a 5-point scale $(1=$ not like me at all to $5=$ very much like me). CFA results indicated that the standardized factor loadings of three items were lower than .40. And these items were deleted in subsequent analyses. All factor loadings of the refined model were significant with excellent model fit $(\mathrm{NNFI}=.95, \mathrm{CFI}=.96$, SRMR $=.04$, RMSEA $=$ .05). Standardized loadings of the remaining 11 items ranged from .42 to .76 . Reliability of the refined measure was good (Cronbach’s $\alpha=.82$ ).

Parent-child relationship quality. To measure the quality of the parent-child relationship, we modified the scale from Armsden and Greenberg (1987). Participants rated five statements in terms of the degree to which each statement described their relationships with parents $(1=$ almost never or never true to $6=$ always true $)$. This measure assessed the closeness of the parent-child relationship and a higher score indicated a closer relationship between the respondent and his/her parents. CFA results indicated that all factor loadings were significant with good model fit $(\mathrm{NNFI}=.92$, CFI $=.96$, SRMR $=.04$, RMSEA $=.10)$. Standardized loadings ranged from .62 to .87. Reliability of the measure was excellent (Cronbach’s $\alpha=.90$ ).

Demographics and control variables. Demographic variables that might affect the dependent variables, including gender and family socioeconomic status (housing types were used as a proxy for this variable), were measured and controlled for in the statistical analysis. In 
addition, the levels (time spent) of participants' general media use and use of SNSs were controlled for, since prior research has shown a positive relationship between media exposure and young people's materialism. Participants reported a daily average of the amount of time they spent on the commonly used media, including watching television (free broadcast and paid channels); watching video clips, TV programs, and movies downloaded from the Internet; browsing the Internet; and reading printed and online magazines. Participants responded on a 5point scale $(1=$ rarely to 5 = more than 4 hours $)$. A composite measure formed by averaging participants' responses to these four items assessed the level of media use. Respondents also reported the daily average of the amount of time they spent on SNSs (e.g., Facebook, Twitter, and Instagram) by responding to a 6 -point scale $(1=$ less than 30 minutes to $6=$ more than 2 hours). Table 1 reports the descriptive statistics of all the measures. The scale items used in the subsequent statistical analysis appear in Appendix.

$<$ Insert Table 1 about here $>$

\section{Analysis and Results}

We used structural equation modeling analysis (SEM) to test the hypotheses. The advantage of this analysis is its ability to control for measurement errors while estimating both direct and indirect (mediation) effects of consumption-oriented SNS use simultaneously. SEM analysis is superior to the causal step approach (Baron \& Kenny, 1986) in testing mediation because SEM provides direct statistical tests for the mediation effect rather than relying on indirect inference from a set of regression results. The statistical tests for the parameter estimates are also more robust with less bias (Cheung \& Lau, 2008; Hayes, 2009). SEM analysis includes the Sobel test, which assesses the statistical significance of the indirect effects stipulated in H1b. 
The structural models depicted in Figure 1 were estimated by SEM using software EQS 6.1. Control variables (i.e., gender, socioeconomic status, level of media use, level of SNS use) were included as observable variables in the analysis so as to partial out their effects on materialism and social perception. Before assessing the validity of the structural models, we assessed the measurement model, which included the five latent factors represented by the multiitem measures described in the previous section. CFA results indicated good model fit (NNFI = $.90, \mathrm{CFI}=.92$, SRMR $=.04, \mathrm{RMSEA}=.05)$. Factor loadings for all observable variables were significant.

<Insert Figure 1 about here>

Regarding the structural models, SEM results indicated that structural model 1 (Figure 1) had acceptable model fit $(\mathrm{NNFI}=.90 ; \mathrm{CFI}=.92$, SRMR $=.05$, RMSEA $=.06)$ and the path coefficient, representing the overall effect of consumption-oriented SNS use on materialism, was significant $\left(\gamma_{1,1}=.34, \mathrm{z}=7.60, p<.01\right)$. Nevertheless, this significant effect could be attributed to the omitted mediation variable in the model. Therefore, we included both the direct and indirect effects of consumption-oriented SNS use in model 2. Results showed that structural model 2 (Figure 1) had acceptable model fit $(\mathrm{NNFI}=.90, \mathrm{CFI}=.91$, SRMR $=.05$, RMSEA $=$ .06). The path coefficient for the effect of consumption-oriented SNS use on social perception was significant $\left(\gamma_{1,1}=.52, \mathrm{z}=10.90, p<.01\right)$ and the coefficient for the effect of social perception on materialism was also significant $\left(\beta_{2,1}=0.55, \mathrm{z}=9.66, p<.01\right)$. The Sobel test showed that the indirect effect of consumption-oriented SNS use on materialism, mediated by social perception, was significant $\left(\gamma_{1,1} \times \beta_{2,1}=.29, \mathrm{z}=7.33, p<.01\right)$. The direct effect of consumption-oriented SNS use when the indirect effect was controlled for was non-significant $\left(\gamma_{2,1}=.05, \mathrm{~ns}\right)$. The total variance $\left(R^{2}\right)$ of materialism and social perception explained by the 
independent and control variables was .36 and .29 respectively. With respect to the control variables, materialism was positively associated with family socioeconomic status $(\beta=0.11, \mathrm{z}=$ 3.30, $p<.01)$ and time spent on SNSs $(\beta=0.10, \mathrm{z}=2.40, p<.05)$. Materialism was higher for females $(\beta=-.09, \mathrm{z}=2.73, p<.01)$. In addition, social perception was significantly associated with gender and was higher for females $(\beta=-.10, \mathrm{z}=2.18, p<.05)$. Overall, these results confirmed that social perception fully mediated the impact of consumption-oriented SNS use on materialism, supporting H1b. Consumption-oriented SNS use had an overall positive effect on materialism (total effect $=.34, \mathrm{z}=4.62, p<.01$ ) but its direct effect was not significant. Thus, H1a was partly supported.

Multi-group analysis in SEM tested H2 and H3. To test H2, we created distinct groups of parent-child relationship quality by dividing the sample into three groups with low, medium, and high levels of parent-child relationship quality. To retain as many observations in the sample as possible, the cutoff points were set to be 0.5 standard deviation above and below the mean value of parent-child relationship quality for the high $(N=318)$ and low $(N=356)$ relationship quality groups. Then, we tested invariance of the three path estimates (i.e., $\gamma_{1,1}, \gamma_{2,1}, \beta_{2,1}$ in model 2) of the structural model between the high and low relationship quality groups. To identify the specific path(s) that differed between the two groups, we assessed the incremental change of $\chi^{2}$ statistic associated with the equality constraint for each path using the Lagrange Multiplier (LM) Test. Results of the test indicated that the path between consumption-oriented SNS use and social perception was significantly different $\left(\Delta \chi^{2}=8.38, p<.05\right)$ between the high and low parent-child relationship quality groups while the other paths were not significantly different between the two groups. The effect of consumption-oriented SNS use on social perception was weaker for the high relationship quality group (high relationship quality: $\gamma_{1,1}=.47$, low 
relationship quality: $\left.\gamma_{1,1}=.68\right)$. Therefore, the smaller overall effect of consumption-oriented SNS use on materialism for users with high parent-child relationship quality (total effect high relationship quality $=.34$, total effect low relationship quality $=.48$ ) was attributed to the weaker association between consumption-oriented SNS use and social perception among these users. Thus, H2 was supported.

To test H3, we created distinct groups of self-regulation by dividing the sample into three groups with low, medium, and high levels of self-regulation. The cutoff points for the high $(N=$ 335) and low $(N=332)$ self-regulation groups were 0.5 standard deviation above and below the mean value of self-regulation respectively. We then assessed equality of the path estimates of the structural model between the high and low self-regulation groups. Results of the LM Test indicated that the path between consumption-oriented SNS use and social perception was significantly different $\left(\Delta \chi^{2}=2.79, p<.10\right)$ between the high and low self-regulation groups while the other paths did not differ between the two groups. The effect of consumption-oriented SNS use on social perception was weaker for users with high self-regulation competence (high self-regulation: $\gamma_{1,1}=.44$, low self-regulation: $\left.\gamma_{1,1}=.53\right)$. Therefore, the smaller overall effect of consumption-oriented SNS use on materialism for users with high self-regulation competence (total effect $_{\text {high self-regulation }}=.25$, total effect low self-regulation $=.35$ ) was attributed to the weaker association between consumption-oriented SNS use and social perception among these users. H3 was thus supported. Overall, these results demonstrated that parent-child relationship quality and self-regulation negatively moderate the indirect effects of consumption-oriented SNS use on materialism.

\section{Discussion}


Since youths have increasingly relied on SNSs to seek news, entertainment, marketing messages, and social support, these networked media have considerable influence on young users' beliefs and behaviors. Previous studies often consider the SNS as a socialization agent that possesses the power to shape young people's cognitions, emotions, and behaviors and have examined the antecedents of SNS use, the effects of SNS use and the underlying mechanisms, as well as how individual and social factors reinforce or dampen the media effects of SNSs (Valkenburg \& Peter, 2013; Valkenburg, Peter, \& Walther, 2016).

Adding to prior research that examines various uses of SNSs, the present study specifically focuses on individuals' use of SNSs to fulfill their need to communicate with peers regarding their consumption experiences, and it considers the implications of this use for young people’s beliefs about material life. A new measure was created and validated to assess consumption-oriented SNS use. The measure reflects a higher-order construct with two forms of consumption-centric communication as sub-dimensions: personal communication with peers and non-personal communication with marketers. These two forms of communication together constitute consumption-oriented SNS use. The findings of this study indicate that after the effects of demographics and other media use variables are accounted for, consumption-oriented SNS use has an overall positive effect on young people's materialism. Such a media effect is attributed to individuals' elevated perception of their peers' spending and consumption levels. Importantly, the mediation effect is negatively moderated by parent-child relationship quality and selfregulation competence.

Grounding our hypotheses in cultivation theory (Gerbner et al., 1994; Gerbner, 1998), the present study shows that the amount of time spent on social media, in particular SNSs, and the level of consumption-oriented use are associated with young people's materialism and social 
perception. This finding is noteworthy, as networked media like SNSs differ markedly from traditional mass media like broadcast television. Most images and content appearing on SNSs are generated by users' social networks amid increasing infiltration of commercial content. In contrast, in traditional media like television, the majority of television programs portray lives of fictional characters in drama and advertising (Gerbner et al., 1994; Shrum et al., 2011). In addition, whereas watching television or reading a magazine is largely a passive process, communication on SNSs is bilateral, or even multilateral among users' networks, and users are often actively involved in content creation and sharing. Despite these differences, our findings reveal that SNS use can strongly influence users' value judgements regarding material possessions and consumption, and such media effects are consistent with the social cognitive perspective of cultivation theory (O’Guinn \& Shrum, 1997; Shrum, 1995; Shrum, 2001).

Another key set of findings pertains to our investigation of the social and dispositional factors that could mitigate the adverse impact of frequent SNS use among youths. The concurrent examination of parent-child relationship quality and self-regulation ability advances an understanding of how and when media effects on SNSs would influence individuals' beliefs and attitudes regarding consumption. In line with prior research highlighting the significant roles of parenting styles and self-control in curbing materialistic tendencies among young people and adolescents (Dittmar et al., 2014; Faber \& Vohs, 2011), our findings validate parent-child relationship quality and self-regulation competence as moderators that reduce the harmful effects of consumption-oriented SNS use. More important, the findings illustrate that such negative moderation occurs because the moderators lower the level of social perception triggered by consumption-oriented SNS use. 
Although the present study did not directly test the contentions of cultivation theory, it adds new insights to previous studies of media's cultivation effects in several ways. First, the findings confirm that, after controlling for the amount of time spent on the media, use of social media specifically to access marketing messages and to communicate with peers about consumption topics increases users' materialism. Thus, research on media effects should examine multiple ways in which users actively consume media rather than focusing on the amount of time that users passively spend on media. This scrutiny is especially important for investigations of social media, which allow and encourage users to create content and to be a conduit for disseminating content. Second, this study demonstrates that social perception fully accounts for the effect of consumption-oriented SNS use on young users' materialism. To our knowledge, this study is the first to validate the mediating role of SNS users' perception of peers' spending in the relationship between SNS use and materialism. Thus, our findings extend prior research that attributes television viewers' materialism to their elevated perception of affluence in society—a perception that results from television viewing (O’Guinn \& Shrum, 1997). Third, this study demonstrates the role of family (parent-child relationships) and personal (self-regulation) factors in mitigating the negative consequences of SNS use. Given the paucity of research examining family and personal factors as boundary conditions for cultivation effects (Morgan \& Shanahan, 2010), our study enlightens future research by underscoring the importance of taking into account the traits of users in studying cultivation processes induced by mass media.

Findings of this study have several substantive implications. First, the study’s findings suggest that parents exert a positive influence on their children's values, possibly by providing an educational and supportive family environment (Collins \& Laursen, 2004). This influence 
extends into the children's adulthood, weakening the association between SNS use and materialism. Our findings are in line with the parental mediation literature, which demonstrates that parents can reduce undesirable media effects on their children, such as aggression (Nathanson, 2004) and online risks (Shin \& Lwin, 2016). In addition, parents are important socialization agents in terms of encouraging their children to internalize norms on healthy, socially responsible behaviors (Kam, Basinger, \& Abendschein, 2015). The insights offered by our study provide parents with an opportunity to reconsider their roles as socialization agents in the changing media environment and to carefully examine their current parenting practices. We suggest that, to foster healthier use of SNSs, parents should be proactive in helping children understand both positive and negative aspects of newer forms of media by adopting mediation strategies based on open discussions and mutual understanding (Shin \& Lwin, 2016). In addition, our findings provide new insights that suggest warm and caring family relationships are effective in preventing children from suffering negative repercussions from the use of SNSs. This effect probably occurs because close family relationships help parents practice active mediation (i.e., talking to and discussing with children about media), thereby influencing children's media attitudes and behaviors (Fujioka \& Austin, 2002). Such autonomy-supportive mediation tends to lead children to be more responsive to parental requests than restrictive mediation (i.e., setting rules regarding media use), which often results in psychological reactance among children (Shin \& Lwin, 2016).

The current study sheds light on the role of self-regulation competence in guiding young people's media use. Specifically, the results show that self-regulation would help youths avoid the adverse impact of SNS use arising from exposure to material images and messages on SNSs and from communicating with peers on consumption topics. The study also indicates that close 
parent-child relationships encourage young people to subordinate materialistic values to other values vital to psychological health (Dittmar et al., 2014). Therefore, even though consumptionoriented communication on SNSs could lead youths to endorse materialistic values, this harmful impact may not be prevalent—it could be lessened if youths possess protective psychological or social mechanisms that shield them from developing damaging perceptions of peers’ consumption levels.

Findings of the current study provide insights for public agencies concerned about the negative impact of networked media on young people and adolescents. While we recognize that SNSs provide users with certain benefits, including fulfilling the need to belong and the need for self-presentation, our findings indicate the potential for inducement of harmful psychological effects. In addition to experiencing elevated materialism, heavy SNS users also tend to compare their spending and consumption behaviors with their peers, with potential consequences of lower self-esteem and well-being (Fox \& Moreland, 2015). Therefore, to prevent negative repercussions from young people's heavy use of SNSs, we suggest that government agencies and educational institutions consider introducing programs that help youths develop their ability to regulate their emotions and behaviors. Such programs can be school-based, as part of characterbuilding efforts targeted at youths, or can occur at a community level. Additionally, policy makers should consider implementing school-based workshops and information sessions to educate and support parents in guiding young family members through the rapidly evolving digital landscape. Self-help materials such as online resources can also be developed to support parents' efforts to cultivate understanding and nurturing family relationships. Such initiatives would strengthen parents' confidence in dealing with digital media issues within the family and thus create higher quality of parent-child communication. 
This study has several limitations. First, owing to the cross-sectional nature of the data, the empirical results cannot confirm a causal relationship between SNS use and materialism. While it is theoretically justifiable to hypothesize consumption-related SNS use to be an antecedent to social perception and materialism, our results cannot rule out the possibility that the relationship between SNS use and materialism could be bilaterally reinforcing in nature. Conceivably, materialistic individuals might be more inclined to post or look for messages related to consumerism owing to selective use of media. ${ }^{1}$ The reinforcing spiral model of Slater (2015) suggests that individuals' attitudes central to self-identity would determine their media use, which in turn reinforces such attitudes in a feedback loop. Therefore, future research should consider using longitudinal data to validate a causal relationship between consumption-related SNS use and materialism.

Second, our data were collected in Singapore, and thus the generalizability of the findings to other international contexts warrants further assessment. Although Singapore emphasizes a strong work ethic, the country's prevailing consumer culture and aspiration to the Western lifestyle place increasing weight on materialism and hedonic consumption (Keng et al., 2000; Li et al., 2011). This unique socio-cultural environment might compel young adults to compare their financial status and material possessions with those of peers and the wider society, resulting in strong influences from consumption-oriented use of SNSs and other media.

Third, our survey respondents were college students. Compared with other age groups and social classes, college students may have higher aspirations for financial success and be more optimistic about future achievement. At the same time, college students might undergo more frequent self-evaluations in their transition to adulthood. Prior research has suggested that peer acceptance is crucial to youths' social-identity formation at key developmental stages and

\footnotetext{
${ }^{1}$ We thank an anonymous reviewer for providing this interesting insight.
} 
thus motivates them to apply peers’ consumption behaviors as a frame of reference (Banerjee \& Dittmar, 2008). Since peers are influential consumer socialization agents, young SNS users are likely to pay frequent attention to the consumption-related content their peers share. Therefore, it is important to understand how developmental characteristics of individuals are associated with consumption-related communication on SNSs and the impact of such communication

(Valkenburg \& Peter, 2013). On a different note, since the respondents were not identified by a random sampling process and limited to college students, the demographic profile of our sample is not wholly representative of the entire population of young adults in Singapore. Therefore, further studies are needed to assess the extent to which our findings are generalizable to different demographic groups.

Finally, this study focuses on the role of parent-child relationship quality in mitigating the detrimental impact of SNS use and thus did not examine the implications of the larger milieu of parental mediation and family communication for young people’s SNS use. As prior research indicates that parental mediation influences adolescents' use of the Internet and SNSs (Chng, Li, Liau, \& Khoo, 2015; Shin \& Ismail, 2014), future research should extend work to include these considerations. 


\section{References}

Allen, J. P., \& Hauser, S. T., Bell, K. L. \& O’Connor, T. G. (1994). Longitudinal assessment of autonomy and relatedness in adolescent-family interactions as predictors of adolescent ego development and self-esteem. Child Development, 65, 179-194. doi:10.2307/1131374

Armsden, G. C., \& Greenberg, M. T. (1987). The inventory of parent and peer attachment: Individual differences and their relationship to psychological well-being in adolescence. Journal of Youth and Adolescence, 16, 427-454. doi:10.1007/BF02202939

Bandura, A., Caprara, G. V., Barbaranelli, C., Pastorelli, C., \& Regalia, C. (2001). Sociocognitive self-regulatory mechanisms governing transgressive behavior. Journal of Personality and Social Psychology, 80, 125-135. doi:10.1037/0022-3514.80.1.125

Banerjee, R., \& Dittmar, H. (2008). Individual differences in children's materialism: The role of peer relations. Personality and Social Psychology Bulletin, 34(1), 17-31. doi:10.1177/0146167207309196

Barkley, R. A. (2004). Attention-deficit/hyperactivity disorder and self-regulation: Taking an evolutionary perspective on executive functioning. In R. F. Baumeister \& K. D. Vohs (Eds), Handbook of self-regulation: research, theory, and applications (pp. 301-323). New York, NY: Guilford Press.

Baron, R. M., \& Kenny, D. A. (1986). The moderator-mediator variable distinction in social psychological research: Conceptual, strategic, and statistical considerations. Journal of Personality and Social Psychology, 51, 1173-1182. doi:10.1037/0022-3514.51.6.1173

Bauer, I. M., \& Baumeister, R. F. (2011). Attentional control and self-regulation. In K. D. Vohs \& R. F. Baumeister (Eds.), Handbook of self-regulation: research, theory, and applications (pp. 64-82). New York, NY: Guilford Press. 
Baumeister, R. F., \& Heatherton, T. F. (1996). Self-regulation failure: An overview.

Psychological Inquiry, 7(1), 1-15. doi:10.1207/s15327965pli0701_1

Beukeboom, C. J., Kerkhof, P., \& de Vries, M. (2015). Does a virtual like cause actual liking?

How following a brand's Facebook updates enhances brand evaluations and purchase intention. Journal of Interactive Marketing, 32, 26-36. doi:10.1016/j.intmar.2015.09.003

Beullens, K., Roe, K., \& Van den Bulck, J. (2011). The impact of adolescents’ news and action movie viewing on risky driving behavior: A longitudinal study. Human Communication Research, 37(4), 488-508. doi:10.1111/j.1468-2958.2011.01412.x

Blair, C., \& Diamond, A. (2008). Biological processes in prevention and intervention: The promotion of self-regulation as a means of preventing school failure. Development and Psychopathology, 20, 899-911. doi:10.1017/S0954579408000436

Blair, C., \& Ursache, A. (2011). Attentional control and self-regulation. In K. D. Vohs \& R. F. Baumeister (Eds.), Handbook of self-regulation: research, theory, and applications (pp. 300-320). New York, NY: Guilford Press.

Bode, L., Vraga, E. K., Borah, P., \& Shah, D. V. (2014). A new space for political behavior: Political social networking and its democratic consequences. Journal of ComputerMediated Communication, 19, 414-429. doi:10.1111/jcc4.12048

Bollen, K. A. (1989). Structural equations with latent variables. Wiley-Interscience.

boyd, D. M., \& Ellison, N. B. (2007). Social network sites: Definition, history, and scholarship. Journal of Computer-Mediated Communication, 13, 210-230. doi:10.1111/j.10836101.2007.00393.x 
Brandtzæg, P. B. (2012). Social networking sites: Their users and social implications-A

longitudinal study. Journal of Computer-Mediated Communication, 17, 467-488. doi: 10.1111/j.1083-6101.2012.01580.x

Bridgett, D. J., Burt, N. M., Edwards, E. S., \& Deater-Deckard, K. (2015). Intergenerational transmission of self-regulation: A multidisciplinary review and integrative conceptual framework. Psychological Bulletin, 141, 602-654. doi:10.1037/a0038662

Brown, J. D., \& L’Engle, K. L. (2009). X-rated sexual attitudes and behaviors associated with U.S. early adolescents’ exposure to sexually explicit media. Communication Research, 36, 129-151. doi:10.1177/0093650208326465

Buijzen, M., Schuurman, J., \& Bomhof, E. (2008). Associations between children's television advertising exposure and their food consumption patterns: A household diary-survey study. Appetite, 50(2-3), 231-239. doi:10.1016/j.appet.2007.07.006

Buijzen, M., \& Valkenburg, P. M. (2003). The unintended effects of television advertising. Communication Research, 30, 483-503. doi:10.1177/0093650203256361

Buijzen, M., \& Valkenburg, P. M. (2005). Parental mediation of undesired advertising effects. Journal of Broadcasting \& Electronic Media, 49(2), 153-165. doi:10.1207/s15506878jobem4902_1

Burroughs, J. E., \& Rindfleisch, A. (2002). Materialism and well-being: A conflicting values perspective. Journal of Consumer Research, 29, 348-370. doi:10.1086/344429

Chaplin, L. N., \& John, D. R. (2010). Interpersonal influences on adolescent materialism: A new look at the role of parents and peers. Journal of Consumer Psychology, 20(2), 176-184. doi:10.1016/j.jcps.2010.02.002 
Cheung, G. W., \& Lau, R. S. (2007). Testing mediation and suppression effects of latent variables: Bootstrapping with structural equation models. Organizational Research Methods, 11, 296-325. doi:10.1177/1094428107300343

Chia, S. C. (2010). How social influence mediates media effects on adolescents' materialism. Communication Research, 37, 400-419. doi:10.1177/0093650210362463

Chng, G. S., Li, D., Liau, A. K., \& Khoo, A. (2015). Moderating effects of the family environment for parental mediation and pathological internet use in youths. Cyberpsychology, Behavior, and Social Networking, 18(1), 30-36. doi:10.1089/cyber.2014.0368

Chou, H., \& Edge, N. (2012). “They are happier and having better lives than I am”: The impact of using Facebook on perceptions of others’ lives. CyberPsychology, Behavior, and Social Networking, 15, 117-121. doi:10.1089/cyber.2011.0324

Collins, W. A., \& Laursen, B. (2004). Parent-adolescent relationships and influences. In R. M. Lerner (Ed.), Handbook of adolescent psychology (pp.331-361). Hoboken, NY: John Wiley \& Sons.

De Vries, D. A., \& Kühne, R. (2015). Facebook and self-perception: Individual susceptibility to negative social comparison on Facebook. Personality and Individual Differences, 86, 217-221. doi:10.1016/j.paid.2015.05.029

Dittmar, H. (2007). The costs of consumer culture and the “cage within”: The impact of the material “good life” and “body perfect” ideals on individuals’ identity and well-being. Psychological Inquiry, 18(1), 23-31. doi:10.1080/10478400701389045 
Dittmar, H., Bond, R., Hurst, M., \& Kasser, T. (2014). The relationship between materialism and personal well-being: A meta-analysis. Journal of Personality and Social Psychology, 107, 879-924. doi:10.1037/a0037409

Dubow, E. F., Huesmann, L. R., \& Greenwood, D. (2007). Media and youth socialization: Underlying processes and moderators of effects. In J. E. Grusec \& P. D. Hastings (Eds.), Handbook of socialization: theory and research (pp. 404-430). New York, NY: The Guilford Press.

Dvorak, R. D., \& Day, A. M. (2014). Marijuana and self-regulation: Examining likelihood and intensity of use and problems. Addictive Behaviors, 39, 709-712. doi:10.1016/j.addbeh.2013.11.001

Ellison, N. B., \& boyd, D. M. (2013). Sociality through social network sites. In W. H. Dutton (Ed.), The Oxford Handbook of Internet Studies (pp. 151-172). Oxford: Oxford University Press.

Ellison, N. B., Vitak, J., Gray, R., \& Lampe, C. (2014). Cultivating social resources on social network sites: Facebook relationship maintenance behaviors and their role in social capital processes. Journal of Computer-Mediated Communication, 19, 855-870. doi:10.1111/jcc4.12078

Faber, R. J., \& Vohs, K. D. (2011). Self-regulation and spending: Evidence from impulsive and compulsive buying. In R. F. Baumeister \& K. D. Vohs (Eds.), Handbook of selfregulation: research, theory, and applications (pp. 537-550). New York, NY: Guilford Press. 
Fardouly, J., Diedrichs, P. C., Vartanian, L. R., \& Halliwell, E. (2015). Social comparisons on social media: The impact of Facebook on young women's body image concerns and mood. Body Image, 13, 38-45. doi:10.1016/j.bodyim.2014.12.002

Farrow, H., \& Yuan, Y. C. (2011). Building stronger ties with alumni through Facebook to increase volunteerism and charitable giving. Journal of Computer-Mediated Communication, 16, 445-464. doi:10.1111/j.1083-6101.2011.01550.x

Fox, J., \& Moreland, J. J. (2015). The dark side of social networking sites: An exploration of the relational and psychological stressors associated with Facebook use and affordances. Computers in Human Behavior, 45, 168-176. doi:10.1016/j.chb.2014.11.083

Fujioka, Y., \& Austin, E. W. (2002). The relationship of family communication patterns to parental mediation styles. Communication Research, 29, 642-665. doi:10.1177/009365002237830

Gerbner, G. (1998). Cultivation analysis: An overview. Mass Communication and Society, 1(34), 175-194. doi:10.1080/15205436.1998.9677855

Gerbner, G., Gross, L., Morgan, M., \& Signorielli, N. (1994). Growing up with television: The cultivation perspective. In J. Bryant \& D. Zillmann (Eds.), Media effects: Advances in theory and research (pp. 17-41). Hillsdale, NJ: Erlbaum.

Greene, N. (2012, December 11). The new consumer: How social media has impacted consumerism. Retrieved from http://socialmediastrategiessummit.com/blog/the-newconsumer-how-social-media-has-impacted-consumerism/

Haferkamp, N., Eimler, S. C., Papadakis, A., \& Kruck, J. V. (2012). Men are from Mars, women are from Venus? Examining gender differences in self-presentation on social networking 
sites. CyberPsychology, Behavior and Social Networking, 15, 91-98.

doi:10.1089/cyber.2011.0151

Hayes, A. F. (2009). Beyond Baron and Kenny: Statistical Mediation Analysis in the New Millennium. Communication Monographs, 76, 408-420.

doi:10.1080/03637750903310360

Hirschman, E. C., \& Thompson, C. J. (1997). Why media matter: Toward a richer understanding of consumers' relationships with advertising and mass media. Journal of Advertising, 26(1), 43-60. doi:10.1080/00913367.1997.10673517

Johar, G. V., Maheswaran, D., \& Peracchio, L. A. (2006). Mapping the frontiers: Theoretical advances in consumer research on memory, affect, and persuasion. Journal of Consumer Research, 33(1), 139-149. doi:10.1086/500493

Kam, J. A., Basinger, E. D., \& Abendschein, B. (2015). Do adolescent perceptions of parents’ alcohol consumption undermine or enhance what parents say about alcohol? The interaction between verbal and nonverbal messages. Communication Research. Advanced online publication. doi:10.1177/0093650214565922

Kasser, T., Ryan, R. M., Zax, M., \& Sameroff, A. J. (1995). The relations of maternal and social environments to late adolescents' materialistic and prosocial values. Developmental Psychology, 31, 907-914. doi:10.1037/0012-1649.31.6.907

Keng, K. A., Jung, K., Jiuan, T. S., \& Wirtz, J. (2000). The influence of materialistic inclination on values, life satisfaction and aspirations: An empirical analysis. Social Indicators Research, 49, 317-333. doi:10.1023/A:1006956602509 
Kim, J. W., \& Chock, T. M. (2015). Body image 2.0: Associations between social grooming on Facebook and body image concerns. Computers in Human Behavior, 48, 331-339. doi:10.1016/j.chb.2015.01.009

Kim, Y., Hsu, S., \& Gil de Zúñiga, H. (2013). Influence of social media use on discussion network heterogeneity and civic engagement: The moderating role of personality traits. Journal of Communication, 63, 498-516. doi:10.1111/jcom.12034

Lamborn, S. D., Mounts, N. S., Steinberg, L., \& Dornbusch, S. M. (1991). Patterns of competence and adjustment among adolescents from authoritative, authoritarian, indulgent, and neglectful families. Child Development, 62, 1049-1065. doi:10.1111/j.1467-8624.1991.tb01588.x

LaRose, R., Lin, C. A., \& Eastin, M. S. (2003). Unregulated internet usage: Addiction, habit, or deficient self-regulation? Media Psychology, 5, 225-253. doi:10.1207/S1532785XMEP0503_01

Lee, C-J., \& Niederdeppe, J. (2011). Genre-specific cultivation effects: Lagged associations between overall TV viewing, local TV news viewing, and fatalistic beliefs about cancer prevention. Communication Research, 38, 731-753. doi:10.1177/0093650210384990

Lewis, K., Kaufman, J., Gonzalez, M., Wimmer, A., \& Christakis, N. (2008). Tastes, ties, and time: A new social network dataset using Facebook.com. Social Networks, 30, 330-342. doi:10.1016/j.socnet.2008.07.002

Li, N. P., Patel, L., Balliet, D., Tov, W., \& Scollon, C. N. (2011). The incompatibility of materialism and the desire for children: Psychological insights into the fertility discrepancy among modern countries. Social Indicators Research, 101, 391-404. doi:10.1007/s11205-010-9665-9 
Li, X., Li, D., \& Newman, J. (2013). Parental behavioral and psychological control and problematic internet use among Chinese adolescents: The mediating role of self-control. CyberPsychology, Behavior, and Social Networking, 16, 442-447. doi:10.1089/cyber.2012.0293

Lwin, M. O., Stanaland, A. J. S., \&, Miyazakic, A. D. (2008). Protecting children's privacy online: How parental mediation strategies affect website safeguard effectiveness. Journal of Retailing, 84(2), 205-217. doi:10.1016/j.jretai.2008.04.004

Martins, N., \& Harrison, K. (2011). Racial and gender differences in the relationship between children's television use and self-esteem: A longitudinal panel study. Communication Research, 39, 338-357. doi:10.1177/0093650211401376

Moilanen, K. L. (2007). The adolescent self-regulatory inventory: The development and validation of a questionnaire of short-term and long-term self-regulation. Journal of Youth and Adolescence, 36, 835-846. doi:10.1007/s10964-006-9107-9

Morgan, M., \& Shanahan, J. (2010). The state of cultivation. Journal of Broadcasting \& Electronic Media, 54, 337-355. doi:10.1080/08838151003735018

Morgan, M., Shanahan, J., \& Signorielli, N. (2015). Yesterday's new cultivation, tomorrow. Mass Communication and Society, 18, 674-699. doi:10.1080/15205436.2015.1072725

Nadkarni, A., \& Hofmann, S. G. (2012). Why do people use Facebook? Personality and Individual Differences, 52, 243-249. doi:10.1016/j.paid.2011.11.007

Nathanson, A. I. (1999). Identifying and explaining the relationship between parental mediation and children’s aggression. Communication Research, 26, 124-143. doi:10.1177/009365099026002002 
Nathanson, A. I. (2004). Factual and evaluative approaches to modifying children's responses to violent television. Journal of Communication, 54, 321-336. doi:10.1111/j.14602466.2004.tb02631.x

National Youth Council (2014).Youth.sg: The state of youth in Singapore. Retrieved from https://www.resourceportal.nyc.sg/nycp/ShowDoc/WLP+Repository/nyc/resources_fs/ny s2013/statshandbook/

Novak, S. P., \& Clayton, R. R. (2001). The influence of school environment and self-regulation on transitions between stages of cigarette smoking: A multilevel analysis. Health Psychology, 20(3), 196-207. doi:10.1037/0278-6133.20.3.196

O’Guinn, T. C., \& Shrum, L. J. (1997). The role of television in the construction of consumer reality. Journal of Consumer Research, 23(4), 278-294. doi:10.1086/209483

Opree, S. J., Buijzen, M., Van Reijmersdal, E. A., \& Valkenburg, P. M. (2013). Children’s advertising exposure, advertised product desire, and materialism: A longitudinal study. Communication Research, 41(5), 717-735. doi:10.1177/0093650213479129

Pew Research Center. (2015). Retrieved from http://www.pewinternet.org/data-trend/socialmedia/social-media-use-by-age-group/

Pingree, R. J. (2007). How messages affect their senders: A more general model of message effects and implications for deliberation. Communication Theory, 17, 439-461. doi:10.1111/j.1468-2885.2007.00306.x

Quinn, P. D., \& Fromme, K. (2010). Self-regulation as a protective factor against risky drinking and sexual behavior. Psychology of Addictive Behaviors, 24, 376-385. doi:10.1037/a0018547 
Richins, M. L. (2004). The material values scale: Measurement properties and development of a short Form. Journal of Consumer Research, 31, 209-219. doi:10.1086/383436

Rindfleisch, A., Burroughs, J. E., \& Denton, F. (1997). Family structure, materialism, and compulsive consumption. Journal of Consumer Research, 23, 312-325. doi:10.1086/209486

Shin, W., \& Lwin, M. O. (2016). How does "talking about the Internet with others" affect teenagers' experience of online risks? The role of active mediation by parents, peers, and school teachers. New Media \& Society. Advanced online publication. doi:

$10.1177 / 1461444815626612$

Shin, W., \& Kang, H. (2016). Adolescents’ privacy concerns and information disclosure online: The role of parents and the Internet. Computers in Human Behavior, 54, 114-123. doi:10.1016/j.chb.2015.07.062

Shin, W., \& Ismail, N. (2014). Exploring the role of parents and peers in young adolescents’ risk taking on social networking sites. CyberPsychology, Behavior, and Social Networking, 17, 578-583. doi:10.1089/cyber.2014.0095

Shrum, L. J. (1995). Assessing the social influence of television: A social cognition perspective on cultivation effects. Communication Research, 22, 402-429.

doi:10.1177/009365095022004002

Shrum, L. J. (2001). Processing strategy moderates the cultivation effect. Human Communication Research, 27, 94-120. doi:10.1111/j.1468-2958.2001.tb00777.x

Shrum, L. J, Burroughs, J. E., \& Rindfleisch, A. (2005). Television’s cultivation of material values. Journal of Consumer Research, 32, 473-479. doi:10.1086/497559 
Shrum, L. J., Lee, J., Burroughs, J. E., \& Rindfleisch, A. (2011). An online process model of second-order cultivation effects: How television cultivates materialism and its consequences for life satisfaction. Human Communication Research, 37, 34-57. doi:10.1111/j.1468-2958.2010.01392.x

Sirgy, M. J., Gurel-Atay, E., Webb, D., Cicic, M., Husic, M., Ekici, A., Herrmann, A., Hegazy, I., Lee, D., \& Johar, J. S. (2012). Linking advertising, materialism, and life satisfaction. Social Indicators Research, 107, 79-101. doi:10.1007/s11205-011-9829-2

Slater, M. D. (2015). Reinforcing spirals model: Conceptualizing the relationship between media content exposure and the development and maintenance of attitudes. Media Psychology, 18, 370-395. doi:10.1080/15213269.2014.897236

Slater, M. D., \& Hayes, A. F. (2010). The influence of youth music television viewership on changes in cigarette use and association with smoking peers: A social identity, reinforcing spirals perspective. Communication Research, 37, 751-773. doi:10.1177/0093650210375953

Slater, M. D., Henry, K. L., Swaim, R. C., \& Anderson, L. L. (2003). Violent media content and aggressiveness in adolescents: A downward spiral model. Communication Research, 30, 713-736. doi:10.1177/0093650203258281

Smith, A. N., Fischer, E., \& Yongjian, C. (2012). How does brand-related user-generated content differ across YouTube, Facebook, and Twitter? Journal of Interactive Marketing, 26(2), 102-113. doi:10.1016/j.intmar.2012.01.002

Valkenburg, P. M., Krcmar, M., \& De Roos, S. (1998). The impact of a cultural children’s program and adult mediation on children's knowledge of and attitudes towards opera. 
Journal of Broadcasting \& Electronic Media, 42, 315-326.

doi:10.1080/08838159809364452

Valkenburg, P. M. \& Peter, J. (2013). The differential susceptibility to media effects model. Journal of Communication, 63, 221-243. doi:10.1111/jcom.12024

Valkenburg, P. M., Peter, J., \& Walther, J. B. (2016). Media effects: Theory and research. Annual Review of Psychology, 67, 315-338. doi:10.1146/annurev-psych-122414-033608

We are social: digital, social and mobile. (2015). Retrieved from http://wearesocial.sg/blog/2015/01/digital-social-mobile-2015/\#more-10068/

Wills, T. A., Pokhrel, P., Morehouse, E. \& Fenster, B. (2011). Behavioral and emotional regulation and adolescent substance use problems: A test of moderation effects in a dualprocess model. Psychology of Addictive Behaviors, 25, 279-292. doi:10.1037/a0022870

Yao, M. Z., He, J., Ko, D. M., \& Pang, K. (2014). The influence of personality, parental behaviors, and self-esteem on internet addiction: A study of Chinese college students. CyberPsychology, Behavior, and Social Networking, 17, 104-110. doi:10.1089/cyber.2012.0710

70\% of Singaporeans are shopaholics. (2011). Retrieved from http://sbr.com.sg/retail/news/70-singaporeans-are-shopaholics/ 
Table 1. Descriptive Statistics of all Measures

\begin{tabular}{|c|c|c|c|}
\hline Measure & Scale range & $M(S D)$ & $\begin{array}{c}\text { Composite } \\
\text { relability }\end{array}$ \\
\hline Consumption-oriented SNS use & 1.00 to 5.00 & $2.00(0.42)$ & 0.79 \\
\hline \multicolumn{4}{|l|}{ Subscale 1} \\
\hline Subscale 2 & 1.00 to 5.00 & $2.25(0.20)$ & 0.68 \\
\hline Materialism & 1.00 to 6.00 & $3.83(0.34)$ & 0.83 \\
\hline Social perception & 1.00 to 6.00 & $2.26(0.53)$ & 0.78 \\
\hline Self-regulation & 1.00 to 5.00 & $3.44(0.26)$ & 0.80 \\
\hline Parent-child relationship quality & 1.00 to 5.00 & $3.68(0.42)$ & 0.85 \\
\hline \multirow[t]{2}{*}{ Gender } & 1 = Male, & $1.54(0.50)$ & - \\
\hline & $2=$ Female & & \\
\hline Family socioeconomic status & 1.00 to 6.00 & $3.10(1.42)$ & - \\
\hline \multicolumn{4}{|l|}{ 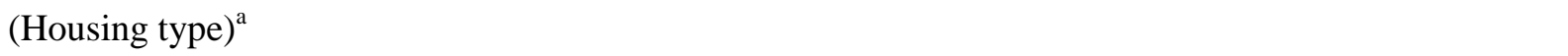 } \\
\hline Time spent on media (media use) ${ }^{\mathrm{a}}$ & 1.00 to 5.00 & $2.76(0.77)$ & - \\
\hline Time spent on SNSs (SNS use) ${ }^{\mathrm{a}}$ & 1.00 to 6.00 & $4.50(1.50)$ & - \\
\hline
\end{tabular}




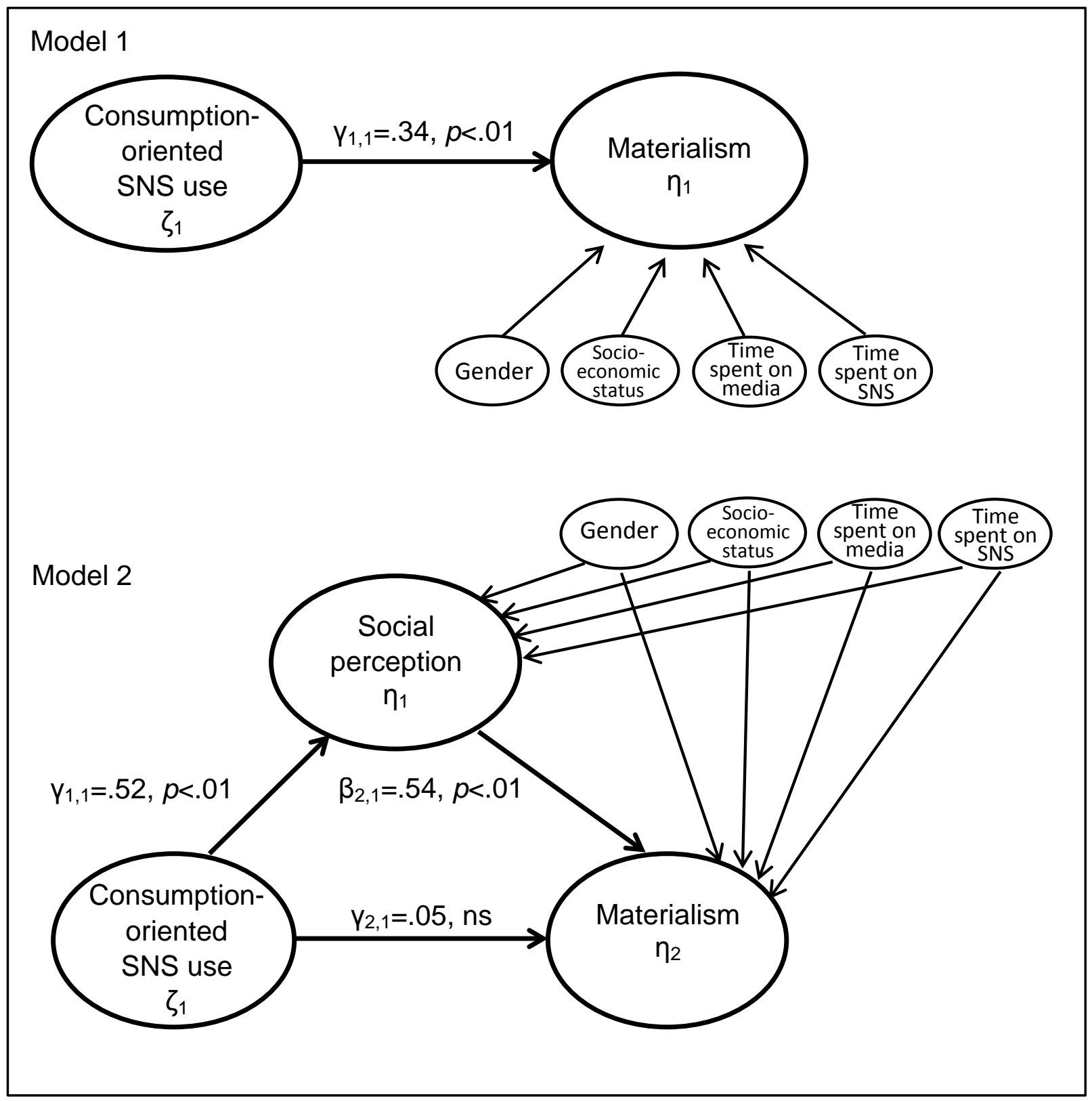

Figure 1. Path Diagram of Structural Models

Note. The path coefficients are standardized coefficients. For simplicity, the observed variables of the latent factors and their error terms were not depicted. 
Appendix

Multi-item Measures.

Construct and composite items

Consumption-oriented SNS use

Subscale 1

Post photos of goods or clothing that you have just purchased.

Post photos of goods or clothing that you like when you shop around.

Forward ads or news about products, shopping, and spending.

Comment on friends' posts about products, shopping, and spending.

Read friends' posts about products, shopping, and spending.

Instant online chat with friends on topics about products, shopping, and spending.

Subscale 2

Read the posts or tweets shared from the brands that you like.

Pay attention to ads and visit websites linked to those ads.

\section{Materialism}

My life would be better if I owned certain things I don't have.

Some of the most important achievements in life include acquiring material possessions.

I like to own things that impress people.

I admire people who own expensive homes, cars, and clothes.

Buying things gives me a lot of pleasure.

I like a lot of luxury in my life.

I would be happier if I could afford to buy more things.

It sometimes bothers me quite a bit that I cannot afford to buy all the things I want.

\section{Social Perception}

It is hard to keep up with my friends' spending habits.

My friends spend far more than I do.

I find my peers buy new things very often.

\section{Self-regulation}

If something isn't going according to my plans, I change my actions to try and reach my goal.

I can find ways to make myself study even when my friends want to go out.

When I have a serious disagreement with someone, I can talk calmly about it without losing control.

I can stay focused on my work even when it is dull.

I work carefully when I know something will be tricky.

I am usually aware of my feelings before I let them out.

In class, I can concentrate on my work even if my friends are talking.

When I have a big project, I can keep working on it.

When I am excited about reaching a goal, it is easy to start working toward it.

I can find a way to stick with my plans and goals, even when it is tough.

I can resist doing something when I know I shouldn't do it.

\section{Parent-child Relationship Quality}

I am satisfied with the relationships with my parents.

I can talk to my parents about most aspects of my life.

My parents care about me.

My parents understand what I need and want.

I seek help from my parents when I have troubles. 


\section{University Library}

\section{- M M N E R VA A gateway to Melbourne's research publications}

Minerva Access is the Institutional Repository of The University of Melbourne

Author/s:

Ho, D.,;SHIN, W;Lwin, M. O.,

Title:

Social Networking Site Use and Materialistic Values among Youth: The Safeguarding Role of the Parent\#Child Relationship and Self-Regulation

Date:

2019

Citation:

Ho, D., , SHIN, W. \& Lwin, M. O., (2019). Social Networking Site Use and Materialistic Values among Youth: The Safeguarding Role of the Parent\#Child Relationship and Self-Regulation. Communication Research, 46 (8), pp.1119-1144. https:// doi.org/10.1177/0093650216683775.

Persistent Link:

http://hdl.handle.net/11343/120656 